\title{
A METHOD TO IMPROVE IRON COMPLIANCE IN TREATING IRON DEFICIENCY ANAEMIA IN PREGNANCY
}

\author{
Deepthi Balakrishnan ${ }^{1}$
}

${ }_{1}^{1}$ Associate Professor, Department of Obstetrics and Gynaecology, Sree Uthradom Thirunal Academy of Medical Sciences, Vattappara, Kerala, India.

\begin{abstract}
BACKGROUND
ABSTRACT

Anaemia among pregnant women is a serious global health concern. Iron deficiency is the most prevalent nutritional deficiency on the globe. In India, pregnant women are amongst the most vulnerable population for iron deficiency anaemia. Even though iron supplements are prescribed, the compliance to therapy is inconsistent. Since India has a predominant rural population, shortage of medical manpower and lack of healthcare facilities may contribute to poor compliance with therapy.
\end{abstract}

\section{MATERIALS AND METHODS}

An observational study was conducted with 140 pregnant anemic women, from a rural area of SUT medical college, Thiruvananthapuram, India. Direct observers were assigned as volunteers, who monitored consumption of oral iron supplementation tablets by pregnant women. The direct observer was an adult in the family who was willing to participate. A detailed history and baseline investigations were done before the initiation of study and periodical assessment of haemoglobin levels was done to evaluate progress and monitor haemoglobin levels.

\section{RESULTS}

The mean adherence rate and haemoglobin levels in the direct observers' group were higher compared to the control group, across all visits. The mean haemoglobin values of participants in study group during $1^{\text {st }}$ visit was $8.97 \mathrm{gm} \%$, whereas in control group, it was $8.98 \mathrm{gm} \%$; In the $2^{\text {nd }}$ visit, mean haemoglobin level in the study group was $9.47 \mathrm{gm} \%$ and $9.18 \mathrm{gm} \%$ in the control group; In the $3^{\text {rd }}$ visit, mean haemoglobin was 9.99 gm\% in the study group and 9.32 gm\% in control group. There was no statistical difference in the mean haemoglobin values between two groups in the first two visits. Although the mean haemoglobin values were

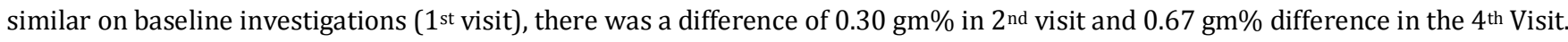
The difference in haemoglobin values at 4 th visit was statistically significant.

\section{CONCLUSION}

It is suggested that assigning a direct observer, as a volunteer for monitoring and delivering oral iron supplementation, amplifies the adherence of pregnant women to oral iron tablets.

\section{KEY WORDS}

Anaemia, Compliance, Monitoring, Supervision, Direct Observer.

HOW TO CITE THIS ARTICLE: Balakrishnan D. A method to improve iron compliance in treating iron deficiency anaemia in pregnancy. J. Evolution Med. Dent. Sci. 2019;8(05):298-305, DOI: 10.14260/jemds/2019/66

\section{BACKGROUND}

Iron deficiency is the most prevalent nutritional deficiency on the globe. ${ }^{1}$ Pregnant women are most susceptible to develop iron deficiency anaemia. Despite large-scale health interventions, the incidence of iron deficiency anaemia continues to raise in developing countries. ${ }^{2}$ According the World Health Organization (WHO) report about 32.4 million pregnant women suffer from anaemia world wide of which 0.8 million are severely anaemic. $350 \%$ cases of anaemia are attributable to iron deficiency anaemia. ${ }^{4}$ It is projected that India has the utmost prevalence of anaemia., 57-96\% among South Asian countries. ${ }^{5}$

'Financial or Other Competing Interest': None.

Submission 02-11-2018, Peer Review 22-01-2019,

Acceptance 28-01-2019, Published 04-02-2019.

Corresponding Author:

Dr. Deepthi Balakrishnan,

Mayuram, HNRA 460,

Pattoor, Vanchiyoor P. $O$.,

Thiruvanathapuram-695035,

Kerala,

India.

E-mail:deepthibalakrishna@gmail.com

DOI: $10.14260 /$ jemds/2019/66

\section{(c) $($ ) $\$$}

Iron deficiency anaemia during pregnancy increases the risk of low birth weight, pre-term birth, maternal and perinatal mortality and poor Apgar score. An estimate by WHO attributes about six lakhs perinatal deaths and 11500 maternal deaths globally to iron deficiency anaemia directly or indirectly. The overall prevalence of anaemia among pregnant women in India is estimated to be about $54.6 \%$ in urban areas, and $59 \%$ in rural areas. ${ }^{6,7}$ There is evidence to suggest that up to $90 \%$ of maternal anaemia may be contributable to inadequate consumption of dietary iron. Furthermore, increased blood loss due to hookworm or schistosomiasis; bleeding haemorrhoids, vitamin deficiencies, HIV and genetic disorders such as sickle cell anaemia and thalassemia add to prevalence of anaemia in pregnant women. ${ }^{8}$

The Standards for Maternal and Neonatal Care developed by the World Health Organization has been working alongside National Nutrition Anaemia Prophylaxis Program in India, for effective deployment of available resources in expediting oral iron and folic acid supplementation for pregnant women in order to improve adherence to prescribed supplements. 8,9

Efforts are being made to generate interest and commitment on the part of health care providers to deliver 
iron/folate tablets, and to improve training of providers in promoting the use of iron supplements, through counselling. However, such degree of commitment on the part of health care system still needs refinement at the grass root level. The concept of how best to assist the women to adhere to a daily regimen of supplement consumption is not fully understood. Looking into other types of daily protocols (e.g., tuberculosis control) may hold some clues to this complex behavioural issue. 10

National programs of iron/folate supplementation for pregnant women have focused on providing supplement medications and amplifying provider performance. However, inadequate awareness about iron deficiency in anaemia, combined with medical delivery system which is not sufficient to cater the health needs of the entire population, has actively contributed to decreased compliance for iron therapy among pregnant women in developing countries. ${ }^{8}$ Compliance to therapy is one of the important factors that affect the outcome of therapy. Compliance can be defined as the extent to which a patient's behaviour coincides with medical advice. In case of tuberculosis, non-compliance may also result in acquired drug resistance requiring more prolong and expensive therapy that is less likely to be successful than the treatment of drug susceptible tuberculosis. Therefore, the Directly Observed Treatment Short Course was designed to reduce the rate of treatment failure, relapse, and drug resistance. ${ }^{11}$

To increase the compliance for iron tablets, there is an impending need to develop specific tools and approaches to address the difficulties of a daily regimen. Some studies indicated that forgetfulness was a significant barrier for consumption of iron tablets. ${ }^{12}$ Researchers have suggested that direct supervision helped pregnant women adhere to the iron tablets consumption. Considering all the interventions done to improve adherence, this study aims to monitor compliance with the consumption of iron tablets. Though there are many alternative ways of supplementing iron and folic acid, all of them may not be cost-effective. With the available resources, a better way of delivery system is warranted to improve compliance. One of the main components in iron supplement delivery system would be monitoring and evaluation. Therefore, appointing a direct observer from the community itself may be cost-effective. The primary objective of this study was to document the effect on adherence of directly observing patients taking iron therapy and to monitor the haemoglobin status of pregnant women.

Iron compliance is one of the major factors contributing to the effectiveness of iron supplementation programme. Some studies on iron compliance have opinionated that better delivery system of iron tablets is the need of the hour. Seldom there have been studies which have focused on iron supplementation interventions with the help of a direct observer for the traditional method of delivering iron supplements. These studies have been discussed in this section to provide a broad-based conceptual understanding of the needs for and the advantages of directly observed iron therapy. The reviews are related generally to the overall population and specifically to the pregnant women.

Factors contributing for low/non-adherence to iron supplements

In the course of advocating a direct observation for validating the consumption of nutritional supplements like iron, we also have to consider a significant number of factors that may invariably affect the adherence to these supplements. A study conducted among low-income group of women in USA during 2005, on pill count adherence to prenatal multivitamin/ mineral supplement use, the researchers reported that ethnicity, nulligravidity, smoking, educational and marital status, affected compliance with prescribed medication. The study was monitored using a pill bottle fitted with Medical Event Monitoring System. The results indicated that side effects were distributed equally in different ethnic groups, but the adherence showed no association with side effects. Since the study involved no intervention with direct observers, an extension of the method is to observe and record if the adherence to iron supplements can be strengthened by direct observation. 13

A qualitative study on women's perceptions of iron deficiency and anaemia prevention and control in eight developing countries describes the major reasons for women not continuing iron tablets consumption are poor access to supplies (i.e., low utilization of antenatal care services or inadequate supplies at facilities), the form of the tablet (i.e., unappealing taste, smell, or colour), side effects (e.g., gastrointestinal problems), fear (e.g., high birth weight, difficult delivery, harm to the foetus), recovery (i.e., discontinuation of supplements as a result of improvement in symptoms) and behaviour (i.e., forgetting or not wanting to take the tablets). ${ }^{14}$ In the nation-wide surveys of Latin American countries, it is observed that women are reluctant to accept iron tablets from sources outside the government health system, fearing poor quality control and lack of medical supervision. ${ }^{15}$ In South India, where the private sector is well developed at the community level, the opposite is true. Potential consumers of supplements are suspicious of the quality of government-supplied pharmaceuticals. In such instances, tablets procured and distributed through NGOs, purchased from private clinics, or in the marketplace are regarded safer. 16

In developing countries like India, there are various reasons that effectively contribute for decreased adherence to iron supplementation including, misunderstanding of instructions, side effects, cultural beliefs, and inconvenient dosing regimens. Inadequate training, access, and motivation on the part of health professionals supplement the inherent patient factors, to amplify the severity of the low/nonadherence. 17,18

Dealing with non-compliance issues

Typically, non-compliance (or non-adherence) with medical advice is assumed to reflect patient's lack of knowledge, inability to retain medical instructions, or other behavioural factors. Recent research suggests that compliance (or not) with medical advice is the result of rational decision-making by the patient about the costs and benefits of prescribed actions, depending upon individual socio-cultural circumstances. It is suggested that "more open, cooperative doctor-patient relationships" are the key to improved compliance. Finding ways to improve the patient-provider relationship through "negotiation and accommodation" must be found. ${ }^{19}$

A study done in Bangladesh during 2002, to study the effect of adverse events on compliance, showed that gastrointestinal side-effects were not significantly associated with compliance. Compliance was monitored with a counting device, electronically pinned to the pill bottle, which recorded 
the date and time, whenever the bottle was opened. 20

Empirical evidence for directly observed therapy

Even though there are not many studies that have explored the direct observation to monitor iron supplementation, there is ample evidence to suggest the validity of such methods in ensuring better drug compliance and adherence. A study done in Philippines in 2008 to evaluate the effectiveness of a redesigned iron supplementation delivery system for pregnant women showed that pregnant women in the experimental area were four times more likely to take iron tablets $(\mathrm{OR}=3.79)$ and sixteen times more likely to being monitored for iron intake $(\mathrm{OR}=16.86)$ compared to the control. In this study 1180 pregnant women were given iron/folic acid tablets daily through the redesigned ISDS in the experimental areas and the existing ISDS in the control areas. ${ }^{21}$

The impact of a weekly iron-folic acid supplement delivered with social marketing to Cambodian women in 2005 , revealed that supplementation was increasingly effective among women of higher socioeconomic status (SES). Among higher SES schoolgirls, 58\% took the supplements, compared with $49 \%$ for lower SES. Social marketing program promoting weekly iron-folic acid supplementation improved haemoglobin levels in women of reproductive age in Cambodia. 22

The concept of seeking help of community women as "Volunteers" was pioneered in India during 1998, at the St John's Medical College, Bangalore. The authors identified Community Health Volunteers (CHVs) with special predetermined criteria (e.g. willingness and enthusiasm even being a mother and having family approval). Village leaders, government functionaries, Traditional Birth Attendants were given priority and selected in many villages as they already enjoyed an excellent relationship with women in the community and were trusted caregivers during pregnancy. 23 Under a Mother Care-supported project in Haryana, India, the Survival for Women and Children Foundation (SWACH) adapted the DOTS strategy for anti-tuberculosis treatment, to deliver iron supplements. The project implemented personally observed treatment [POT], as a mechanism to combat the difficulties of a daily iron regimen. Adolescent girls on their way to and from school stopped by the homes of pregnant women who had been diagnosed with moderate anaemia. They supervised the consumption of twice-daily iron supplements and provided information about iron and anaemia. With this treatment strategy, they were able to achieve nearly $100 \%$ compliance.8,14 Iron supplementation reports across the globe have been suggesting that communication efforts must be expanded to increase understanding of the importance of taking supplements and to address any fears or misconceptions relating to supplementation. Overall, measures are recommended to increase the capacity of individuals and communities to define, analyse and act to address their own health needs. ${ }^{24}$

\section{Objective}

To observe the effect of monitored iron intake in antenatal anaemic women.

\section{MATERIALS AND METHODS}

The observational study was approved by the Institutional Medical Ethics Committee.

The study was conducted between January 2016 and December 2016. The sample size of 140 was taken for convenience. This 140 Patients were randomly divided into three groups with 140 patients taken as $1^{\text {st }}$ visit group, 121 patients taken as 2 nd visit group, 113 patients taken as $4^{\text {th }}$ visit group, by computer generated numbers.

The pregnant women in the second trimester (after 12 wks.), with mild and moderate anaemia, who attended the antenatal clinic at SUT medical college, Vattapara, Thiruvananthapuram, India, during this period were included for the study. 72 participants in the study group and 68 in the control group at the first visit. These anaemic antenatal women were randomly inducted into the study, after obtaining an informed consent. Pregnant women with history of severe side effects to iron therapy were not included. Additionally, those women currently undergoing iron supplementation were instructed not to participate in the study. At the fourth visit 113(due to drop outs) pregnant women (58 participants in the study group and 55 criteriaindividuals in the control group) were analysed.

\begin{tabular}{|c|c|c|}
\hline & ICMR & WHO \\
\hline Mild & $\mathrm{Hb} \mathrm{10-11} \mathrm{gm/dl}$ & $\mathrm{Hb} \mathrm{9-11} \mathrm{gm/dl}$ \\
\hline Moderate & $\mathrm{Hb} \mathrm{7-10} \mathrm{gm/dl}$ & $\mathrm{Hb} \mathrm{7-9} \mathrm{gm/dl}$ \\
\hline Severe & $\mathrm{Hb} \mathrm{4-7gm/dl}$ & $\mathrm{Hb}<7 \mathrm{gm} / \mathrm{dl}$ \\
\hline Very Severe & $\mathrm{Hb}<4 \mathrm{gm} / \mathrm{dl}$ & \\
\hline \multicolumn{3}{|c|}{ Classification of Anaemia } \\
\hline
\end{tabular}

\section{Materials Included}

1. Health Pro forma.

2. Haemoglobin estimation and peripheral smear.

3. Direct Observer's Calendars.

4. Ferrous ascorbate tablets.

Haemoglobin estimation was done for both the groups at the beginning of the study and depending on their haemoglobin status, strength and frequency of iron tablets were adjusted. The haemoglobin estimation and peripheral smear preparation was carried out by the lab technician. Haemoglobin less than 11 gm \% were given therapeutic dose [2 tablets/ day].25,26 They were advised to take the tablets for 100 days across three intervals starting from $16^{\text {th }}$ week of gestation. ${ }^{25}$ Ferrous ascorbate tablets was given to both the groups. An Antihelminthic drug [400 mg Albendazole - Single dose] was given under supervision at the beginning of the study to both the groups if they were not dewormed within the past 6 months. Peripheral smear was taken from both the groups at the beginning of the study to identify the type of anaemia.

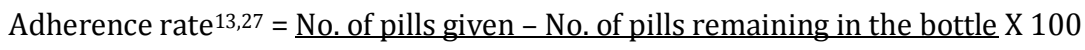

Expected number of pills to be taken 
Detailed questionnaire was used to collect the data and clinical examination was done in the presence of a female attender. In total four visits were undertaken to each pregnant woman in 100 days. At the end of the study,

Haemoglobin estimation was sampled again. The details of each visit are given below.

\section{Visit 1}

Informed consent, history collection, Haemoglobin estimation and peripheral smear examination, ferrous ascorbate tablets for 30 to 35 days, appointing a volunteered direct observer for the Study group and distributing Direct Observer's Calendar of 30 to 35 days in the Study group.

\section{Visit 2}

Calculation of adherence, disqualification of pregnant women from the study who developed severe side effects, ferrous ascorbate tablets for the next 30 to 35 days, distributing Direct Observer's Calendar of 30 to 40 days for study group, and Haemoglobin estimation/ peripheral smear examination.

\section{Visit 3}

Calculation of adherence, prescription ferrous ascorbate tablets for the duration of 30 to 35 days and distribution of Direct Observer's Calendar [30 to 35 days] for Study Group.

\section{Visit 4}

Calculation of adherence rate, Haemoglobin estimation and peripheral smear examination.

\section{Study Group}

Study group was supervised by a direct observer per pregnant woman. The direct observer was an adult from the family, literate individual, staying with the pregnant women in the same house, who accompany her for antenatal checkups. Each pregnant woman was administered iron tablets for 100 days across three intervals and advised to consume daily under direct observation. The observer was given a Direct Observer's Calendar in which a single tick mark or double tick mark was required to enter the data for that day. If the pregnant lady consumed a single dose of iron tablet/day, a single tick mark was written for that particular day and a double tick mark if iron tablets were consumed twice daily. If she missed any dose prescribed for that particular day, a cross mark was made for that specific dose. Following the completion of the stipulated time, the data was collected at the end of each interval for every pregnant woman. Since the direct observer used only the orthographic signs [tick marks/cross mark] it was easily followed by people who were not literate.

\section{Control Group}

After identifying each pregnant woman in her second trimester, iron tablets were prescribed for 100 days, to be consumed across 3 intervals. The pregnant woman was counselled to take the iron tablets regularly and consistently. Periodic visits were undertaken according to the prescription intervals for both the groups. During these visits Iron tablet strips were cross checked for any remaining doses. The adherence to the iron tablets for that particular interval was calculated using the formula.

\section{Socio-Economic Status}

Information regarding per capita income (In Rupees/ month) was collected and socio-economic status was classified using Modified B G Prasad's classification for the study period (2008-09) and it was calculated by Multiplication factor (2008-09) with 1961 Prasad's classification values. ${ }^{28,29}$

\section{Statistical Analysis}

A Chi-Square test and a Students unpaired t test was conducted respectively, A P-value $<0.005$ was taken as significant. SPSS version 17 was used for statistical analysis.

\section{RESULTS}

There were 140 pregnant female participants $(n=140)$. The level of significance was set at a conventional ' $p$ ' value of 0.05 . Since the dependent measure of adherence represents a categorical data with two levels and the levels of haemoglobin, a continuous measure, many other parameters [Demographic profile, antenatal history, general physical examination, systemic examination, etc.] were included in the data collection. These potentially confounding variables were not statistically significant.

There was no statistically significant difference between Study and control group in the distribution of participants according to age and literacy. A large number of participants were in the age group 18-20 years (52.9\%) followed by 21-25 years group (42.9\%). All the participants were literates.

In the current study, the participants were equally distributed in Study and control group, with regard to their Socio-economic status. A higher number of participants were in Class IV (45\%) and Class III (32.1\%) level. There was a statistically significant difference in the distribution of participants among Study and control groups in relation to the family type. Joint families were observed to be similarly distributed. However, nuclear families were identified in higher number in the Study group (34.7\%) compared to the control group (13.2\%);

Iron rich foods such as meats (72.1\%), dried fruits (63.2\%), green leafy vegetables (92.6\%), eggs (52.1\%) were consumed by the participants; whereas ragi $(22.1 \%)$, jaggery (40\%), whole grain cereals $(23.5 \%)$ were consumed in lesser quantity across both groups. Enhancers of iron absorption like meat $(80.7 \%)$, poultry $(57.1 \%)$, fish $(27.9 \%)$, fruits and vegetables rich in Vitamin C $(90 \%)$ were also consumed. Inhibitors of iron absorption like spinach (52.9\%), tea (47.1\%), coffee (15\%), legumes (44.3\%), fibre (35\%), calcium (77.9\%), and zinc $(83.6 \%)$ were consumed by participants similarly in both the groups.

In this study, all participants were identified to have a moderate deficiency of daily calorie consumption. Most of them $(47.9 \%)$ were having a deficiency of $25-34.99 \%$. The protein deficiency was observed in a higher number among all the participants (82.1\%); majority (47.1\%) were observed to have $<15 \%$ deficiency in protein intake. The parameters of protein and calorie deficiency were observed to be similarly distributed among the study and control groups. 
All the participants were registered in their first trimester. The results of this study show that the mean hemoglobin values of participants in study group during $1^{\text {st }}$ visit was $8.97 \mathrm{gm} \%$, whereas in control group, it was 8.98 gm\%; In the $2^{\text {nd }}$ visit, mean hemoglobin level in the study group was $9.48 \mathrm{gm} \%$ and a $9.18 \mathrm{gm} \%$ in the control group; In the $3^{\text {rd }}$ visit, mean hemoglobin was $9.99 \mathrm{gm} \%$ in the study group and $9.32 \mathrm{gm} \%$ in control group. There was no statistical difference in the mean haemoglobin values between two groups in the first two visits. Although the mean haemoglobin values were similar on baseline investigations (1 $1^{\text {st }}$ visit), there was a difference of $0.30 \mathrm{gm} \%$ in $2^{\text {nd }}$ visit and $0.67 \mathrm{gm} \%$ difference in the $4^{\text {th }}$ Visit. This moderate increase was observed in Study. The difference in haemoglobin values at $4^{\text {th }}$ visit was statistically significant.

In this study, there was no statistically significant difference in the distribution of participants according to anemic status, across both groups during $1^{\text {st }}, 2^{\text {nd }}$ and $4^{\text {th }}$ visits. Prevalence of anaemia in Study group was at $1^{\text {st }}$ visit (95.8\%), at $2^{\text {nd }}$ visit $95.2 \%$ and at $4^{\text {th }}$ Visit $82.8 \%$; whereas in control group at $1^{\text {st }}$ Visit (98.5\%), at $2^{\text {nd }}$ visit $94.8 \%$ and at $4^{\text {th }}$ visit $92.6 \%$.

In this study, a statistically significant difference was observed in the distribution of adherence rates among study and control groups. The mean adherence rate in study group during $2^{\text {nd }}$ visit was $78.48 \%$. However, in the control group it was $49.22 \%$. Likewise, during $3^{\text {rd }}$ visit mean adherence rate was $79.13 \%$ in study and $52.75 \%$ in controls. In $4^{\text {th }}$ Visit, the adherence rate was $76.44 \%$ in study group and $53.87 \%$ in control group.

The following reasons were reported by the participants for missing the doses: Forgetfulness was the main reason among the control group (29.3\%). Vomiting was one of the main reasons for failing to adhere to the therapy in the Study group (25.4\%). In the $3^{\text {rd }}$ visit it was noticed that forgetfulness (51.8\%) was the main reason among control group, whereas nausea $(49.2 \%)$ and heart burn (41\%) were more observed in the Study group. In the $4^{\text {th }}$ visit diarrhoea $(24.1 \%)$ and heartburn $(72.4 \%)$ were observed to be the predominant reasons in the study group, whereas forgetfulness $(36.4 \%)$ was the most common reason in the control group.

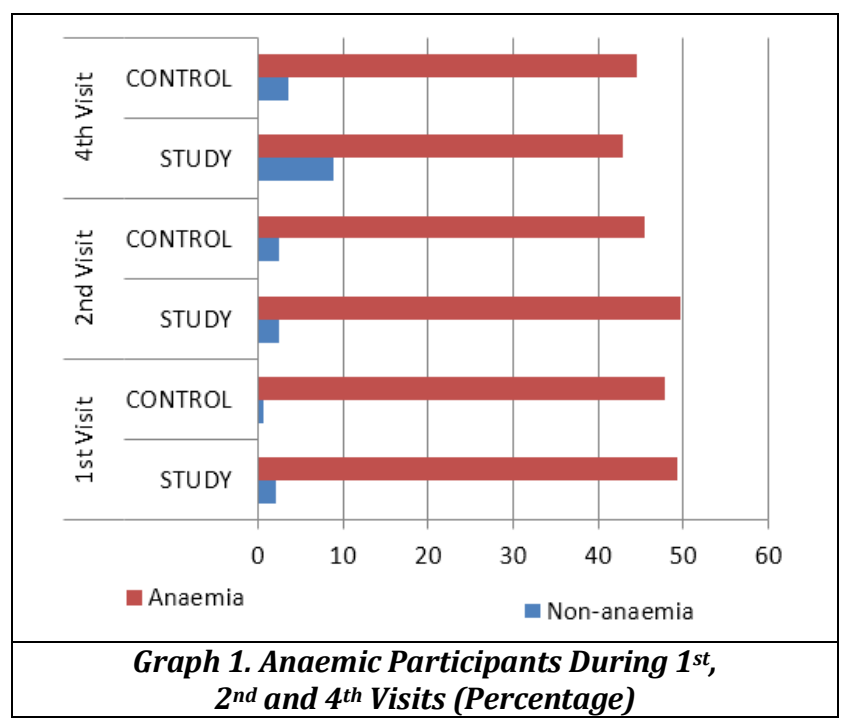

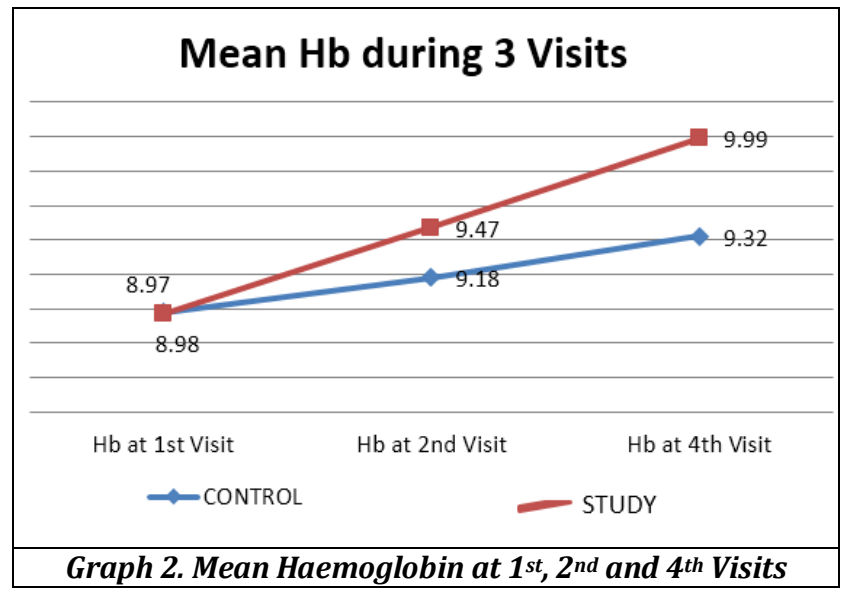

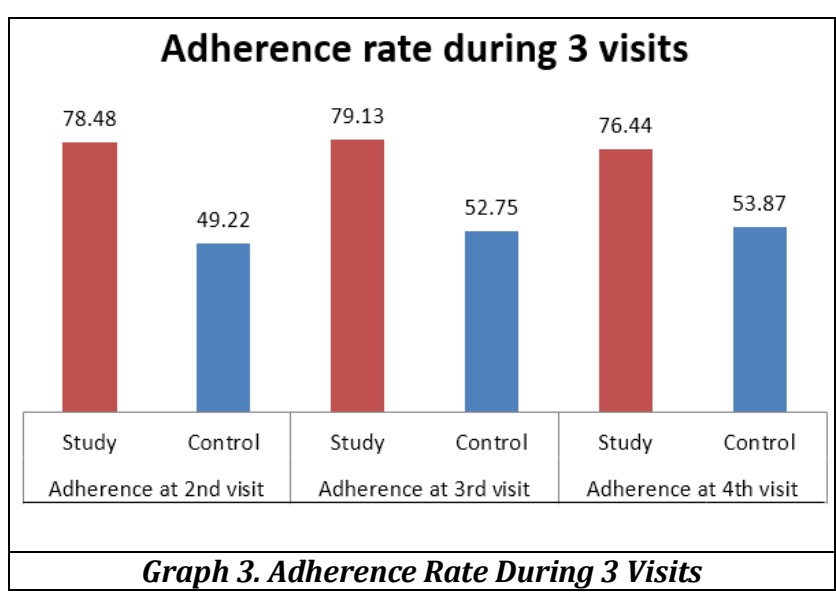

\begin{tabular}{|c|c|c|c|c|c|c|c|}
\hline & \multicolumn{2}{|c|}{$1^{\text {st }}$ Visit } & \multicolumn{2}{|c|}{$2^{\text {nd }}$ Visit } & \multicolumn{2}{|c|}{$4^{\text {th }}$ Visit } \\
\hline & & \begin{tabular}{|l|} 
Study \\
{$[n=72]$}
\end{tabular} & \begin{tabular}{|l} 
Contro \\
{$[\mathrm{n}=68]$}
\end{tabular} & $\begin{array}{l}\text { Study } \\
{[n=63}\end{array}$ & \begin{tabular}{|l} 
Control \\
{$[n=58]$}
\end{tabular} & $\begin{array}{l}\text { Study } \\
{[n=58]}\end{array}$ & $\begin{array}{l}\text { Control } \\
{[n=55]}\end{array}$ \\
\hline \multirow{3}{*}{$\begin{array}{c}\text { Non- } \\
\text { Anaemia }\end{array}$} & No. & 3 & 1 & 3 & 3 & 10 & 5 \\
\hline & $\%$ & 4.2 & 1.5 & 4.8 & 5.2 & 17.2 & 7.4 \\
\hline & $\begin{array}{r}\% \text { of } \\
\text { Total }\end{array}$ & 2.1 & 0.7 & 2.5 & 2.5 & 8.9 & 3.6 \\
\hline \multirow{3}{*}{ Anaemia } & No. & 69 & 67 & 60 & 55 & 48 & 50 \\
\hline & $\%$ & 95.8 & 98.5 & 95.2 & 94.8 & 82.8 & 92.6 \\
\hline & $\begin{array}{c}\text { \% of } \\
\text { Total }\end{array}$ & 49.3 & 47.9 & 49.6 & 45.5 & 42.9 & 44.6 \\
\hline & & \multicolumn{2}{|l|}{$\mathrm{P}=$} & \multicolumn{2}{|l|}{$\mathrm{P}=$} & \multicolumn{2}{|c|}{$\mathrm{P}=0.116$} \\
\hline
\end{tabular}

Table 1. Anaemic Participants During $1^{\text {st }}, 2^{\text {nd }}$ and $4^{\text {th }}$ Visits

\begin{tabular}{|c|c|c|c|c|c|}
\hline & $\begin{array}{c}\text { Sub } \\
\text { Centre }\end{array}$ & $\mathbf{N}$ & Mean & $\begin{array}{c}\text { Std. } \\
\text { Deviation }\end{array}$ & Test \\
\hline \multirow[b]{2}{*}{$\mathrm{Hb}-1$} & Study & 72 & 8.97 & 1.06 & \multirow{2}{*}{$\begin{array}{l}\mathrm{t}=-0.085 \\
\mathrm{DF}=138 \\
\mathrm{P}=0.932\end{array}$} \\
\hline & Control & 68 & 8.98 & 0.93 & \\
\hline \multirow{2}{*}{$\mathrm{Hb}-2$} & Study & 63 & 9.48 & 1.07 & \multirow{2}{*}{$\begin{array}{l}\mathrm{t}=1.527 \\
\mathrm{DF}=119 \\
\mathrm{P}=0.130\end{array}$} \\
\hline & Control & 58 & 9.18 & 0.99 & \\
\hline $\mathrm{Hb}-4$ & $\begin{array}{c}\text { Study } \\
\text { Control }\end{array}$ & $\begin{array}{l}58 \\
55\end{array}$ & $\begin{array}{l}9.99 \\
9.32\end{array}$ & $\begin{array}{l}1.11 \\
1.04\end{array}$ & $\begin{array}{l}\mathrm{t}=2.804 \\
\mathrm{DF}=111 \\
\mathrm{P}=0.006\end{array}$ \\
\hline
\end{tabular}

Table 2. Distribution of Mean Haemoglobin at 1st, $2^{\text {nd }}$ And $4^{\text {th }}$ Visits in Study and Control Groups 


\begin{tabular}{|c|c|c|c|c|c|}
\hline & Groups & $\mathbf{N}$ & Mean & $\begin{array}{c}\text { Std. } \\
\text { Deviation }\end{array}$ & t test \\
\hline \multirow{2}{*}{$\begin{array}{l}\text { Adherence } \\
\text { at } 2^{\text {nd }} \text { Visit }\end{array}$} & 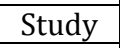 & 63 & 8.48 & 10.32 & \multirow{2}{*}{$\begin{array}{l}\mathrm{t}=12.053 \\
\mathrm{DF}=119 \\
\mathrm{P}=0.000\end{array}$} \\
\hline & Control & 58 & 49.22 & 15.98 & \\
\hline \multirow{2}{*}{$\begin{array}{l}\text { Adherence } \\
\text { at 3rd Visit }\end{array}$} & Study & 61 & 79.13 & 11.77 & \multirow{2}{*}{$\begin{array}{c}\mathrm{t}=10.789 \\
\mathrm{DF}=115 \\
\mathrm{P}=0.000\end{array}$} \\
\hline & Con & 56 & 52.75 & 14.6 & \\
\hline \multirow{2}{*}{$\begin{array}{l}\text { Adherence } \\
\text { at } 4^{\text {th }} \text { Visit }\end{array}$} & Study & 58 & 76.44 & 9.72 & \multirow{2}{*}{$\begin{array}{l}t=9.599 \\
D F=111 \\
P=0.000\end{array}$} \\
\hline & Control & 55 & 53.87 & 14. & \\
\hline
\end{tabular}

Table 3. Distribution of Adherence Rate Among Study and Control Group During $2^{\text {nd }}, 3^{\text {rd }} \& 4^{\text {th }}$ Visits

\section{DISCUSSION}

The current study is a novel method of validation, which was designed to incorporate a new angle to the already existing system of functioning. There is always a possibility of potential confounds right from the stages of ideation, design, and till the completion of the study. Nonetheless, in this study, all possible measures were promptly deployed to remediate and manage possible confounds at all levels with available resources and evidence of similar studies. The tables obtained from the results are discussed in the following section.

The mean adherence rate in study group during $2^{\text {nd }}$ visit was $78.48 \%$ whereas in control group it was $49.22 \%$. Likewise, during $3^{\text {rd }}$ visit, mean adherence rate was $79.13 \%$ in study and $52.75 \%$ in controls. In $4^{\text {th }}$ Visit, the adherence rate was $76.44 \%$ in study group and $53.87 \%$ in control group. This observation leads us to posit that the intervention of a direct observer may have been a prime reason in improving the adherence to the supplement regimen. There has been empirical evidence to support this claim with similar studies. Even though not all of the studies included direct observers, some form of supervision for the treatment was the main reason for adherence to therapy.

Researchers at Panyali, Himachal Pradesh, observed that a total of $87.3 \%$ of the recruited participants completely adhered to the three months iron therapy. ${ }^{30}$ Compliance was defined as total number of patients who completed the therapy, to the total number of patients enrolled and the resulting parameter multiplied by the factor of $100 .{ }^{31}$ In the study done in Vietnam, a total of $73 \%$ of literate women reported high compliance when compared with women who were not literates who showed a $50 \%$ of compliance. 32 The literacy level in both the groups was controlled, as there were approximately similar number of literate women in both groups. In a study conducted in Toronto, the range of pill intake for both groups was zero to $100 \%$, and the mean pill intake for both groups was approximately $50 \%$. Among those who started taking assigned prenatal supplements $73 \%$ were adherent in $35 \mathrm{mg}$ iron group and 76\% were adherent in 60 mg iron group. Among them $>80 \%$ adherence was seen in $37 \%$ in $35 \mathrm{mg}$ group and $38 \%$ in $60 \mathrm{mg}$ iron group. $>50 \%$ adherence was seen in 56\% in $35 \mathrm{mg}$ iron group and $60 \%$ in $60 \mathrm{mg}$ iron group. Participants were controlled for strength of iron supplementation at $100 \mathrm{mg}$. 33

In a study conducted in Philippines, the percentage of women consuming iron and folic acid tablets in control group was $57.4 \%$ and in experimental group $79.2 \%$ after intervention. ${ }^{21}$ However, the follow up of the participants was conducted for 180 days in that study, compared to 100 days in this study [considering actual follow up cases only]. The results of the study conducted in New Delhi, showed that the completion rate of participants who availed oral iron group, was $67.5 \%$ and parenteral iron group was $94.3 \%$ indicating relatively better acceptance for parenteral iron supplementation, a form of direct observance. ${ }^{34}$ The results of the study conducted in Bangladesh suggested that for the supplements provided during week 1 to 4 , daily supplements compliance rate was $61.1 \%$ and for weekly supplements, it was $92.7 \%$. During week 5 to 11 , median compliance in daily group was $65 \%$ and in weekly group was $93 \% .{ }^{20}$

\section{Limitations}

- The main reason for the dropout was relocation of the study participants and it was impossible to trace them.

- Measurement of serum ferritin or serum transferring levels could have given better diagnosis of iron status in the pregnant women. This could not be done because of logistic and feasibility issues.

\section{CONCLUSION}

There was a high prevalence of anaemia among pregnant women (97.1\%). Moderate anaemia was more common among the subjects. All the confounding factors were matched before the study started (religion, woman's age, literacy, per capita income, time and place of ANC registration, toilet facility, wearing footwears, deworming, anaemia at baseline, peripheral smear at baseline, diet, consumption of iron rich foods, enhancers of iron absorption and inhibitors of iron absorption, calorie deficiency, protein deficiency.

It was observed that appointing a direct observer improves the adherence to iron tablets consumption by reducing the factors responsible for non-adherence like forgetfulness, carelessness, etc. It can't reduce the side effects on oral iron tablets, but the pregnant women are motivated and supported to adhere to the prescribed regimen. Though the mean haemoglobin raise in both the groups were statistically not significant initially, it was found that there was statistically significant difference in improving haemoglobin levels in the study group during the last visit.

The present study was done in a rural set up where anaemia prevalence was high. Therefore, a similar replication of this study in other rural areas of the country is feasible and is needed. Even though similar studies have shown better compliance than the present study, the results validate a method, which can be advantageously strategized into the present practice without further compromising on financial or human resources. The strategy is simple, in a sense that the Direct Observers (Volunteers) from the population are to be selected for voluntary and willing participation and cooperation.

Therefore, appointing a direct observer in a rural set up is an effective method to improve the adherence rate of pregnant women to iron tablets consumption. Additionally, it is favorable to be included in the current drug delivery system by effective channelization of man power and with available resources, thus scoring additional points in costbenefit analysis. 


\section{REFERENCES}

[1] Anaemia prevention and control: What Works. Part I Program Guidance. The Population, Health and Nutrition Information (PHNI) Project, Jorge Scientific Corporation with the Futures Group International, John Snow Inc., June 2003.

[2] Gillespie S. Major issues in the control of iron deficiency. Ottawa, Canada: Micronutrient Initiative, 1998.

[3] De Benoist B, McLean E, Egli I, et al. Worldwide prevalence of anaemia 1993-2005: WHO global Database on Anaemia. World Health Organization, Geneva, 2008.

[4] WHO. The Global Prevalence of Anaemia in 2011. Geneva: World Health organization, 2015.

[5] Prevalence of anaemia among pregnant women \% 2016.

http://data.worldbank.org/indicator/SH.PRG.ANEM.

[6] Ministry of Health and Family Welfare. National Family Health Survey (NFHS-3) [cited 2007 Oct 14]. http://www.nfhsindia.org/pdf/IN.pdf

[7] Ministry of Health and Family Welfare. National Family Health Survey (NFHS-3) [cited 2007 Oct 14]. http://www.nfhsindia.org/pdf/KA.pdf

[8] Elder LK. Issues in programming for maternal anaemia. Center for Population, Health and Nutrition. Bureau for Global Programs, Field Support and Research, US: Sept 2000.

[9] Lincetto 0 . Iron and folate supplementation. Integrated Management of Pregnancy and Childbirth (IMPAC). World Health Organization, Geneva: 2002 Oct 14-16.

[10] Kureshy N, Elder L. MotherCare Matters. A quarterly newsletter and literature review on Maternal and Neonatal Health and Nutrition, 2000;8(3-4):1-24.

[11] Pandit N, Choudhary SK. A study of treatment compliance in directly observed therapy for Tuberculosis. Indian J Community Med 2006;31(4):13.

[12] Ghanekar J, Kanani S, Patel S. Toward better compliance with iron-folic acid supplements: Understanding the behavior of poor urban pregnant women through ethnographic models in Vadodara, India. Food and Nutrition Bulletin 2002;23(1):65-72.

[13] Jasti S, Siega-Riz AM, Cogswell ME, et al. Pill count adherence to prenatal multivitamin/mineral supplement use among low-income women. J Nutr 2005;135(5):1093-101.

[14] Galloway R, Dusch E, Elder L, et al. Women's perceptions of iron deficiency and anaemia prevention and control in eight developing countries. Soc Sci Med 2002;55(4):529-44.

[15] Schultink W, Van Der Ree M, Matulessi P, et al. Low compliance with an iron-supplementation program: a study among pregnant women in Jakarta, Indonesia. Am J Clin Nutr 1993;57(2):135-9.

[16] Seck BC, Jackson RT. Determinants of compliance with iron supplementation among pregnant women in Senegal. Public Health Nutrition 2008;11(6):596-605.

[17] Galloway R, McGuire J. Determinants of compliance with iron supplementation: supplies, side effects or psychology? J Soc Sci Med 1994;39(3):381-90.
[18] Yip R. Iron supplementation: country level experiences and lessons learned. J Nutr 2002;132(Suppl 4):859S61S.

[19] O'Connor DM, Savageau JA, Centerbar DB, et al. Lesson in a pill box: teaching about the challenges of medication adherence. Fam Med 2009;41(2):99-104.

[20] Hyder SM, Persson LA, Chowdhury AM, et al. Do sideeffects reduce compliance to iron supplementation? A study of daily-and weekly-dose regimens in pregnancy. J Health Popul Nutr 2002;20(2):175-9.

[21] Risonar MGD, Rayco-Solon P, Tengco LW, et al. Effectiveness of a redesigned iron supplementation delivery system for pregnant women in Negros Occidental, Philippines. Public Health Nutrition 2009;12(7):932-40.

[22] Kanal K, Busch-Hallen J, Cavalli-Sforza T, et al. Weekly Iron-Folic acid supplements to prevent anaemia among Cambodian women in three settings: process and outcomes of social marketing and community mobilization. Nutrition Reviews 2005;63(12 Pt 2):S126-33.

[23] Reducing maternal anaemia through community participation: Bangalore, India. Cited on 24 Oct, 2009, file:///CI/DOCUME 1/GGLEAS 1.TUF/LOCALS 1/T emp/ LWF0000.htm(1 of 6)

[24] Schultink W. Iron-supplementation programmes: compliance of target groups and frequency of tablet intake. Cited on 20 Oct 2009. http://www.idpas.org/pdf/241_Iron_supplementatio n_programmes.pdf

[25] National Institute of Health and Family Welfare. National Nutrition Anaemia Prophylaxis Programme. [Cited 2009 Nov 15]. http://nihfw.nic.in/ndcnihfw/html/Programmes/NationalNutitionAnaemia.h tm.

[26] Gautam VP, Bansal Y, Taneja DK, et al. A study on compliance to iron-folic acid therapy and its effects on anaemia during pregnancy. Indian J Prev Soc Med 2005;36(3-4):102-7.

[27] Huang HY, Maguire MG, Miller ER 3rd, et al. Impact of pill organizers and blister packs on adherence to pill taking in two vitamin supplementation trials. Am J Epidemiol 2000;152(8):780-7.

[28] Kulkarni AP, Barde JP. Text book of community medicine. $2^{\text {nd }}$ edn. Mumbai: Vora Medical Publishers 1998: p. 31.

[29] All India consumer price index. http://www.eximkey.com/budget0910/es/tab53.pdf on $20 / 08 / 2009$.

[30] Agarwal T, Kochar GK, Goel S. Impact of iron supplementation on anaemia during pregnancy. Ethno-Med 2008;2(2):149-51.

[31] Bharti S. Feasibility of "Directly observed home-based twice-daily iron therapy" (DOHBIT) for management of anaemia in rural patients: a pilot study. Indian J of Med Sci 2004;58(10):431-8.

[32] Casey GJ, Phuc TQ, MacGregor L, et al. A free weekly iron-folic acid supplementation and regular deworming program is associated with improved haemoglobin and iron status indicators in Vietnamese women. BMC Public Health 2009;9:261. 
[33] Nguyen P, Nava-Ocampo A, Levy A, et al. Effect of iron on the tolerability of prenatal multivitamins in pregnancy. BMC Pregnancy and Childbirth 2008;8:17.
[34] Sharma JB, Jain S, Mallika V, et al. A prospective, partially randomized study of pregnancy outcomes and hematologic responses to oral and intramuscular iron treatment in moderately anemic pregnant women. Am J Clin Nutr 2004;79(1):116-22. 